\title{
Investigation of Metabolic and Circulatory Parameters That Predict Effects of Dapagliflozin, a Sodium-Glucose Cotransporter 2 Inhibitor, on Blood Glucose and Body Weight in a Retrospective, Multicenter Study
}

Tadachika Kudo $^{1}$, Ichiro Abe ${ }^{1}$, Midori Minezaki ${ }^{1}$, Kaoru Sugimoto ${ }^{1}$, Hideyuki Fujii ${ }^{1}$, Hanako Ohishi ${ }^{1}$, Midori Nakagawa ${ }^{1}$, Saori Yano ${ }^{1}$, Sunao Matsubayashi ${ }^{2}$, Miho Fukudome $^{3}$, Hiroshi Ninomiya ${ }^{3}$, Hidehiro Ishii ${ }^{4}$, Takehiko Kodera ${ }^{5}$, Hisao Ito ${ }^{6}$, Yasutaka Maeda ${ }^{7}$ and Kunihisa Kobayashi ${ }^{1 *}$

${ }^{1}$ Department of Endocrinology and Diabetes Mellitus, Fukuoka University Chikushi Hospital, 1-1-1 Zokumyoin, Chikushino, Fukuoka, 818-8502, Japan

${ }^{2}$ Fukuoka Tokushukai Medical Center, 4-5 Sugukita, Kasuga, Fukuoka, 816-0864, Japan

${ }^{3}$ Hara Hospital, 5-1-15 Shirakibaru, Onojo, Fukuoka, 816-0943, Japan

${ }^{4}$ Saiseikai Futsukaichi Hospital, 3-13-1 Yumachi, Chikushino, Fukuoka, 818-8516, Japan

${ }^{5}$ Kodera Medical Clinic, 1-29-26 Kanzeonji, Dazaifu, Fukuoka, 818-0101, Japan

${ }^{6}$ Ito Medical Clinic, 6-10-1 Harada, Chikushino, Fukuoka, 818-0024, Japan

${ }^{7}$ Clinical Research Center for Diabetes, Clinic Masae Minami, 1-4-6 Heiwa, Minami-ku, Fukuoka, 815-0071, Japan

"Corresponding author: Kunihisa Kobayashi, Department of Endocrinology and Diabetes Mellitus, Fukuoka University Chikushi Hospital, 1-1-1 Zokumyoin, Chikushino, Fukuoka, 818-8502, Japan, Tel: 092-921-1011; Fax: 092-928-0856; E-mail: nihisak@fukuoka-u.ac.jp

Received date: September 23, 2018; Accepted date: November 05, 2018; Published date: November 11, 2018

Copyright: (c) 2018 Kudo T, et al. This is an open-access article distributed under the terms of the Creative Commons Attribution License, which permits unrestricted use, distribution, and reproduction in any medium, provided the original author and source are credited.

\section{Abstract}

Objective: We aimed to investigate the changes in blood glucose levels, body weight, and metabolic and circulatory parameters during daily administration of the sodium-glucose cotransporter 2 inhibitor, dapagliflozin, as well as to examine its safety and the factors that predict its effects on blood glucose and body weight in a retrospective, multicenter study conducted at 6 medical institutions in the Chikushi region of Kyushu, Japan.

Methods: A total of 112 people with type 2 diabetes treated with dapagliflozin participated in the study. Data from blood tests, physical measurements, and other parameters obtained during outpatient visits at the start and after 12 months were retrospectively analyzed to evaluate the efficacy and safety.

Results: The mean age of patients was $56.7 \pm 9.9$ years (mean \pm standard deviation). The glycated hemoglobin $(\mathrm{HbA} 1 \mathrm{c})$ and body mass index $(\mathrm{BMI})$ at baseline were $8.1 \pm 1.2 \%$ and $29.2 \pm 4.6 \mathrm{~kg} / \mathrm{m}^{2}$, respectively. Significant reduction was observed in $\mathrm{HbA} 1 \mathrm{c}(0.66 \%)$ and body weight $(2.9 \mathrm{~kg})(\mathrm{p}<0.01)$ with dapagliflozin administration. After 12 months, blood pressure, liver function parameters (aspartate aminotransferase [AST], alanine aminotransferase [ALT], $\gamma$-glutamyl transpeptidase $[\gamma-G T P])$, uric acid, lipid profile $(p<0.05)$ were significantly improved. Multiple regression analyses showed that high baseline $\mathrm{HbA} 1 \mathrm{c}$ affected the improvement of HbA1c. Additionally, female sex and long disease duration affected BMI improvement. Regarding the safety, none of the 112 subjects exhibited severe adverse effects related to dapagliflozin, and no clinically meaningful changes were observed in the data from blood tests and physical measurements obtained during outpatient visits.

Conclusion: This multicenter study conducted at medical institutions in the Chikushi region of Kyushu confirmed the efficacy and safety of dapagliflozin in clinical practice. We identified baseline $\mathrm{HbA} 1 \mathrm{c}$ level as a factor that affected the change in $\mathrm{HbA1c}$, and sex and disease duration as factors affecting the change in BMI.

Keywords: Dapagliflozin; SGLT2 inhibitor; Type 2 diabetes mellitus; Clinical practice; Multicenter study

\section{Introduction}

Educating and supporting patients with diabetes is extremely important for preventing both acute and chronic diabetic complications [1]. Appropriate blood glucose control in patients with diabetes can be achieved through diet and exercise therapy, and if necessary, with antihyperglycemic agents. All medical professionals involved in diabetes care are responsible for preventing the onset and exacerbation of complications. Sodium-glucose cotransporter 2 (SGLT2) inhibitors suppress the reabsorption of glucose by selectively inhibiting SGLT2 activity on the proximal renal tubules. This results in excretion of excess glucose in the urine, thereby lowering blood glucose levels [2]. Several meta-analyses and systematic reviews have verified the glucose-lowering effects of SGLT2 inhibitors [3-6], and administration of an SGLT2 inhibitor alone was found to have the low risk of hypoglycemia [2]. Besides, SGLT2 inhibitors have been shown to reduce body weight, lower blood pressure, improve the lipid profile, lower uric acid levels, and have other positive effects on metabolism and circulatory dynamics. Therefore, these drugs are expected to lower the risk of cardiovascular events among patients with type 2 diabetes $[7,8]$.

To address the concerns about using SGLT2 inhibitors in elderly people, post marketing surveillance of SGLT2 inhibitor use in elderly patients with type 2 diabetes was conducted and showed safety levels 
Citation: Kudo T, Abe I, Minezaki M, Sugimoto K, Fujii H, et al. (2018) Investigation of Metabolic and Circulatory Parameters That Predict Effects of Dapagliflozin, a Sodium-Glucose Cotransporter 2 Inhibitor, on Blood Glucose and Body Weight in a Retrospective, Multicenter Study. J Diabetes Metab 9: 810. doi:10.4172/2155-6156.1000810

Page 2 of 7

similar to those determined in clinical trials and did not reveal any new safety problems [9-13]. Therefore, SGLT2 inhibitors are considered a useful therapeutic option for patients with type 2 diabetes, including elderly patients. Therefore, the use of SGLT2 inhibitors in clinical practice is expected to expand.

Thus, it is extremely important to verify the safety and efficacy of the daily administration of SGLT2 inhibitors to treat patients with type 2 diabetes with various background characteristics. Furthermore, given the various actions of SGLT2 inhibitors, including improvement of metabolism and circulatory dynamics, a detailed investigation of the changes in blood glucose, body weight, and metabolic and circulatory parameters during SGLT2 inhibitor administration could help investigate other clinical applications of these drugs. Therefore, we conducted a retrospective, multicenter study at 6 medical institutions in the Chikushi region of Kyushu to investigate the changes in blood glucose levels, body weight, metabolic and circulatory parameters, and safety during daily administration of the SGLT2 inhibitor, dapagliflozin.

\section{Methods}

\section{Study design}

This study was a multicenter study including 6 medical institutions (Fukuoka University Chikushi Hospital, Ito Medical Clinic, Kodera Medical Clinic, Saiseikai Futsukaichi Hospital, Hara Hospital, Fukuoka Tokushukai Medical Center) in the Chikushi region of Kyushu, Japan. The study design was a retrospective analysis of data for a maximum of 12 months at the participating institutions (UMIN000025585).

\section{Subjects}

Patients with type 2 diabetes who received dapagliflozin in outpatient care at the aforementioned 6 medical institutions from May 2014 to September 2016 were included. All subjects provided written informed consents. Patient received blood tests at indicated visits in each medical institution before or after meals.

\section{Treatment method}

Oral administration of dapagliflozin was initiated at $5 \mathrm{mg}$ once per day. If the effect was insufficient, the dose was increased to $10 \mathrm{mg}$ once per day while observing the patient's course. We analyzed the data of patients who were administered the same doses of anti-diabetic drugs during the study period.

\section{Parameters assessed}

To retrospectively analyze clinical data from the start of dapagliflozin administration to 12 months, the following parameters were assessed. Changes in glycated hemoglobin (HbAlc), body weight, casual blood glucose, CPR index (fasting C-peptide ( $\mathrm{ng} / \mathrm{mL}$ )/fasting blood glucose $(\mathrm{mg} / \mathrm{dl}) \times 100)$, body mass index $(\mathrm{BMI})$, systolic blood pressure, diastolic blood pressure, pulse rate, aspartate aminotransferase (AST), alanine aminotransaminase (ALT), $\gamma$ glutamyl transpeptidase $(\gamma$-GTP), uric acid, serum creatinine $(\mathrm{Cr})$, estimated glomerular filtration rate (eGFR), urinary albumin (mg/ $\mathrm{gCr}$ ), total cholesterol (total-C), low-density lipoprotein cholesterol (LDL-C), high-density lipoprotein cholesterol (HDL-C), and triglycerides were examined from the start of administration to 12 months. Correlations among change of each parameter from the start of administration to 12 months were investigated. Baseline age, sex, disease duration, HbAlc, BMI, systolic blood pressure, ALT, eGFR, and HDL-C were analyzed to identify the factors that affected the changes in HbAlc and BMI. The incidence of adverse effects was assessed in all patients who received dapagliflozin as an indicator of safety. The definition of diseases is as follows. DKD (diabetic kidney disease) was defined as a urine albumin-to-creatinine ratio $\geq 30 \mathrm{mg} /$ gCr. Dyslipidemia was defined as having total-C $\geq 220 \mathrm{mg} / \mathrm{dl}$, LDL-C $\geq$ $140 \mathrm{mg} / \mathrm{dl}$, triglyceride $\geq 150 \mathrm{mg} / \mathrm{dl}$, or HDL-C $\leq 40 \mathrm{mg} / \mathrm{dl}$. Hypertension was defined as having systolic blood pressure $\geq 140$ $\mathrm{mmHg}$ or diastolic blood pressure $\geq 90 \mathrm{mmHg}$. Obesity + preobesity was defined as BMI $\geq 22 \mathrm{~kg} / \mathrm{m}^{2}$. Fatty liver was diagnosed with abdominal ultrasonography. Hyperuricemia was defined as uric acid $\geq$ $7.0 \mathrm{mg} / \mathrm{dl}$. All individuals with dyslipidemia, hypertension, and hyperuricemia received drug treatment.

\section{Analytical methods}

$\mathrm{HbAlc}$ and body weight were determined at the start of administration and after 1, 3, 6, and 12 months. Data at the start of administration were compared to those after $1,3,6$, and 12 months using analysis of variance (ANOVA; multiplicity adjusted with the Holm method). Other clinical values, BMI, blood pressure, and pulse rate were measured at the start of administration and after 12 months, and data were compared using the paired t-test. Correlations were examined using Spearman's rank correlation coefficient. Patient characteristics that affected the changes in HbAlc and BMI were identified using multiple regression analysis (stepwise method) with baseline age, sex, disease duration, HbAlc, BMI, systolic blood pressure, ALT, eGFR, and HDL-C as the explanatory variables. Data were expressed as the mean \pm standard deviation or number of patients (ratio). Missing values were supplemented using the last observation carried forward method. Statistical analyses were performed using Excel Statistics 2015 ver 2.21 (Bellcurve for Excel). A 2 -tailed 5\% significance level was used.

\section{Ethical considerations}

This study was carried out in accordance with both ethical guidelines based on the Declaration of Helsinki and from Ministry of Health, Labour and Welfare of Japan. Prior to starting the study, approval was obtained from the Fukuoka University Chikushi Hospital ethical review board. To use the data for this study, each institution was notified that the trial would be conducted on an opt-out basis, and patients who continued to visit the institutions received an explanation of the study from their primary physician to obtain consents. Patients' privacy was fully considered such that individual patients could not be identified.

\section{Results}

\section{Subjects}

A total of 112 subjects (63 men and 49 women) with a mean age of $56.7 \pm 9.9$ years, diabetes duration of $10 \pm 6$ years, HbAlc of $8.1 \pm$ $1.2 \%$, and BMI of $29.2 \pm 4.6 \mathrm{~kg} / \mathrm{m}^{2}$ (Table 1) were included. At the start of dapagliflozin administration, the majority of patients were using a biguanide (66.1\%) or dipeptidyl peptidase- 4 inhibitors (54.5\%), with $24.1 \%$ of the patients using insulin (Table 2). The main complications were dyslipidemia (67.9\%), hypertension $(60.7 \%)$, obesity+preobesity (46.4\%), and fatty liver (24.1\%) (Table 3). 
Citation: Kudo T, Abe I, Minezaki M, Sugimoto K, Fujii H, et al. (2018) Investigation of Metabolic and Circulatory Parameters That Predict Effects of Dapagliflozin, a Sodium-Glucose Cotransporter 2 Inhibitor, on Blood Glucose and Body Weight in a Retrospective, Multicenter Study. J Diabetes Metab 9: 810. doi:10.4172/2155-6156.1000810

Page 3 of 7

\begin{tabular}{|c|c|c|}
\hline Characteristics & $\mathbf{n}$ & Values \\
\hline Age (years) & 112 & $56.7 \pm 9.9$ \\
\hline Sex (male/female, $\mathrm{n}[\%])$ & 112 & $63[56.3] / 49[43.8]$ \\
\hline Duration of diabetes (years) & 108 & $10.0 \pm 6.0$ \\
\hline $\mathrm{HbA1c}(\%)$ & 112 & $8.1 \pm 1.2$ \\
\hline Casual plasma glucose $(\mathrm{mg} / \mathrm{dl})$ & 110 & $187.0 \pm 64.4$ \\
\hline CPR index & 25 & $2.1 \pm 1.1$ \\
\hline Body weight (kg) & 104 & $77.3 \pm 12.8$ \\
\hline BMI $\left(\mathrm{kg} / \mathrm{m}^{2}\right)$ & 102 & $29.2 \pm 4.6$ \\
\hline Systolic blood pressure $(\mathrm{mmHg})$ & 105 & $133.1 \pm 14.2$ \\
\hline Diastolic blood pressure $(\mathrm{mmHg})$ & 105 & $79.7 \pm 9.5$ \\
\hline AST (U/I) & 109 & $30.4 \pm 19.6$ \\
\hline $\operatorname{ALT}(U / I)$ & 109 & $35.7 \pm 23.2$ \\
\hline Y-GTP (IU/I) & 111 & $52.8 \pm 84.4$ \\
\hline Uric acid (mg/dl) & 104 & $5.6 \pm 1.4$ \\
\hline Creatinine (mg/dl) & 112 & $0.7 \pm 0.2$ \\
\hline eGFR $\left(\mathrm{ml} / \mathrm{min} / 1.73 \mathrm{~m}^{2}\right)$ & 112 & $83.1 \pm 21.8$ \\
\hline Urine albumin excretion ( $\mathrm{mg} / \mathrm{gCr}$ ) & 80 & $49.2 \pm 61.4$ \\
\hline Total-C (mg/dl) & 66 & $198.5 \pm 33.9$ \\
\hline LDL-C (mg/dl) & 74 & $117.2 \pm 25.4$ \\
\hline HDL-C (mg/dl) & 110 & $52.1 \pm 11.2$ \\
\hline Triglyceride (mg/dl) & 110 & $183.9 \pm 104.9$ \\
\hline
\end{tabular}

\begin{tabular}{|l|c|}
\hline \multicolumn{1}{|c|}{ Comorbidities } & $\mathbf{N}=112$ \\
\hline Neuropathy & $24(21.4)$ \\
\hline Retinopathy & $21(18.6)$ \\
\hline DKD & $42(37.5)$ \\
\hline Dyslipidemia & $76(67.9)$ \\
\hline Hypertension & $68(60.7)$ \\
\hline Obesity+preobesity & $52(46.4)$ \\
\hline Fatty liver & $27(24.1)$ \\
\hline Hyperuricemia & $9(8.0)$ \\
\hline Insomnia & $6(5.4)$ \\
\hline Brain stroke & $4(3.6)$ \\
\hline Myocardial infarction & $3(2.7)$ \\
\hline Angina & $2(1.8)$ \\
\hline Data are expressed as numbers (\%). DKD: diabetic kidney disease. \\
\hline
\end{tabular}

Table 3: Comorbidities at baseline.

\section{HbAlc change}

HbAlc significantly changed from $8.1 \pm 1.2 \%$ at the start of dapagliflozin administration to $7.8 \pm 1,7.6 \pm 1,7.5 \pm 1$ and $7.5 \pm 1 \%$ after $1,3,6$, and 12 months, respectively ( $\mathrm{p}<0.01$; Figure 1 ). The type of anti-diabetic drugs prescribed before dapagliflozin was not related with the changes of $\mathrm{HbAlc}$ and weight after adding dapagliflozin (Supplement 1).

Table 1: Baseline characteristics.

\begin{tabular}{|l|c|}
\hline \multicolumn{1}{|c|}{ Glucose-lowering drugs } & $\mathbf{N = 1 1 2}$ \\
\hline Biguanide & $74(66.1)$ \\
\hline DPP-4 inhibitors & $61(54.5)$ \\
\hline Sulfonylurea & $39(34.8)$ \\
\hline Thiazolidinediones & $11(9.8)$ \\
\hline a-glucosidase inhibitors & $8(7.1)$ \\
\hline Meglitinides & $2(1.8)$ \\
\hline DPP-4 inhibitor+Biguanide & $1(0.9)$ \\
\hline DPP-4 inhibitor+Thiazolidinediones & $1(0.9)$ \\
\hline GLP-1 receptor agonists & $6(5.4)$ \\
\hline Insulin & $27(24.1)$ \\
\hline
\end{tabular}

Table 2:Glucose-lowering drugs used at baseline. Data are expressed as numbers (\%). DPP-4: dipeptidyl peptidase-4, GLP-1: Glucagon-like peptide-1.

\section{Body weight change}

Body weight significantly decreased from $77.3 \pm 12.8 \mathrm{~kg}$ at the start of dapagliflozin administration to $76.0 \pm 12.7,75.0 \pm 12.7,74.6 \pm 12.9$, 
Citation: Kudo T, Abe I, Minezaki M, Sugimoto K, Fujii H, et al. (2018) Investigation of Metabolic and Circulatory Parameters That Predict Effects of Dapagliflozin, a Sodium-Glucose Cotransporter 2 Inhibitor, on Blood Glucose and Body Weight in a Retrospective, Multicenter Study. J Diabetes Metab 9: 810. doi:10.4172/2155-6156.1000810

Page 4 of 7

and $74.3 \pm 12.9 \mathrm{~kg}$ after $1,3,6$, and 12 months, respectively $(\mathrm{p}<0.01$; Figure 2).

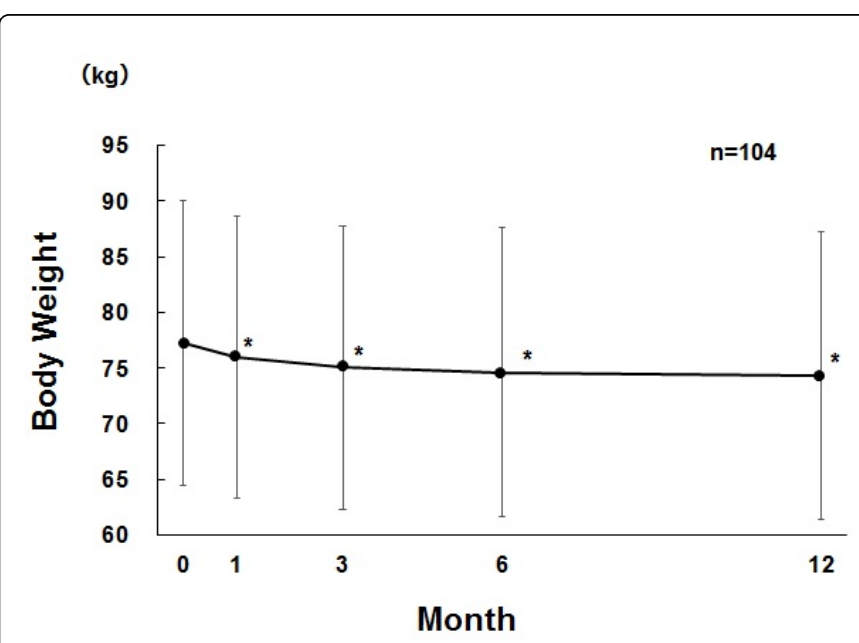

Figure 2: Changes in body weight over time. The data are expressed as the means \pm standard deviation. Missing values were supplemented using the last observation carried forward method. ${ }^{*} \mathrm{p}<0.01$ (vs. start of administration, ANOVA followed by multiplicity test with Holm method).

\section{Changes in blood pressure, pulse rate, and clinical examination}

After 12 months of dapagliflozin administration, blood glucose, BMI, systolic blood pressure, and diastolic blood pressure significantly decreased, compared to those at the start of dapagliflozin administration $(\mathrm{p}<0.05)$ without the changes of pulse rate. HDL-C significantly increased $(\mathrm{p}=0.002)$.

Significant improvements were observed for all the liver function parameters (AST, ALT, and $\gamma$-GTP; $p<0.01$ ). Of the kidney function parameters, only serum $\mathrm{Cr}$ significantly increased $(\mathrm{p}<0.05$; Table 4$)$.

\section{Correlations among the parameters assessed}

Correlations among the changes in various parameters after 12 months of dapagliflozin administration were analyzed using Spearman's rank correlation coefficient (Table 5).

The change in $\mathrm{HbAlc}$ showed a significant positive correlation with changes in ALT, $\gamma$-GTP, and triglycerides $(p<0.05)$ and a significant negative correlation with the change in HDL-C $(\mathrm{p}<0.001)$. The change in body weight showed a significant positive correlation with the change in ALT and $\gamma$-GTP $(p<0.05)$. The change in ALT and $\gamma$-GTP showed a significant positive correlation with LDL-C $(\mathrm{p}<0.05)$.

\section{Patient baseline characteristics that affected the changes in HbAlc and body weight}

Multiple regression analysis (stepwise method) was used to investigate the patient characteristics that affected the changes in
HbAlc. Baseline HbAlc was considered a factor that affected the changes in HbAlc. Patients with higher HbAlc showed greater improvement in $\mathrm{HbAlc}$ than those with lower HbAlc.

Furthermore, sex and disease duration at baseline were identified as factors that affected the changes in BMI. Women and patients with longer disease duration showed greater improvement in BMI than men and patients with shorter disease duration (Table 6).

\section{Safety assessment}

No severe adverse effects related to dapagliflozin administration were observed among the 112 subjects, and there were no clinically meaningful changes in the data from blood tests and physical measurements obtained during outpatient visits.

\begin{tabular}{|c|c|c|c|c|}
\hline Characteristics' & $\mathbf{n}$ & Baseline & 12 months & p-value \\
\hline Casual plasma glucose $(\mathrm{mg} / \mathrm{dl})$ & 110 & $187.0 \pm 64.4$ & $158.7 \pm 51.0$ & $<0.001^{* *}$ \\
\hline CPR index & 7 & $1.90 \pm 0.5$ & $3.60 \pm 2.9$ & 0.183 \\
\hline BMI $\left(\mathrm{kg} / \mathrm{m}^{2}\right)$ & 84 & $29.50 \pm 4.7$ & $28.30 \pm 4.7$ & $<0.001^{* *}$ \\
\hline $\begin{array}{l}\text { Systolic blood pressure } \\
(\mathrm{mmHg})\end{array}$ & 104 & $132.8 \pm 13.8$ & $128.6 \pm 14.4$ & $0.009^{\star *}$ \\
\hline $\begin{array}{l}\text { Diastolic blood pressure } \\
(\mathrm{mmHg})\end{array}$ & 104 & $79.50 \pm 9.10$ & $76.80 \pm 10.2$ & $0.019^{*}$ \\
\hline Pulse (beats/min) & 87 & $81.0 \pm 11.5$ & $80.40 \pm 12.1$ & 0.678 \\
\hline AST (U/I) & 108 & $30.60 \pm 19.6$ & $26.60 \pm 14.8$ & $0.008^{* *}$ \\
\hline ALT $(U / I)$ & 108 & $35.90 \pm 23.2$ & $30.90 \pm 22.7$ & $0.006^{\star *}$ \\
\hline Y-GTP (IU/I) & 110 & $53.20 \pm 84.7$ & $41.60 \pm 48.2$ & $0.005^{\star *}$ \\
\hline Uric acid (mg/dl) & 102 & $5.60 \pm 1.40$ & $5.20 \pm 1.5$ & $<0.001^{* *}$ \\
\hline Creatinine (mg/dl) & 111 & $0.72 \pm 0.22$ & $0.76 \pm 0.26$ & $0.025^{\star}$ \\
\hline eGFR $\left(\mathrm{mL} / \mathrm{min} / 1.73 \mathrm{~m}^{2}\right)$ & 111 & $83.10 \pm 21.9$ & $80.70 \pm 24.1$ & 0.065 \\
\hline $\begin{array}{l}\text { Urinary albumin excretion } \\
\text { (mg/gCre) }\end{array}$ & 63 & $46.40 \pm 57.2$ & $50.10 \pm 96.5$ & 0.73 \\
\hline Total-C (mg/dl) & 65 & $198.20 \pm 34.1$ & $193.6 \pm 30.5$ & 0.113 \\
\hline LDL-C (mg/dl) & 72 & $117.20 \pm 25.7$ & $112.8 \pm 24.8$ & 0.16 \\
\hline HDL-C (mg/dl) & 109 & $51.90 \pm 11.0$ & $54.0 \pm 11.5$ & $0.002^{\star \star}$ \\
\hline Casual triglyceride $(\mathrm{mg} / \mathrm{dl})$ & 109 & $183.8 \pm 105.4$ & $203.1 \pm 256.3$ & 0.294 \\
\hline
\end{tabular}

Data are expressed as the means \pm standard deviation and missing values were complemented by the last observation carried forward method. ${ }^{*} p<0.05$, ${ }^{* *} p<0.01$ (vs. baseline, paired t-test).

Table 4: Changes in clinical parameters. 
Citation: Kudo T, Abe I, Minezaki M, Sugimoto K, Fujii H, et al. (2018) Investigation of Metabolic and Circulatory Parameters That Predict Effects of Dapagliflozin, a Sodium-Glucose Cotransporter 2 Inhibitor, on Blood Glucose and Body Weight in a Retrospective, Multicenter Study. J Diabetes Metab 9: 810. doi:10.4172/2155-6156.1000810

Page 5 of 7

\begin{tabular}{|c|c|c|c|c|c|c|c|c|c|c|c|c|c|c|c|c|c|c|c|}
\hline & $\triangle \mathrm{HbA} 1 \mathrm{c}$ & $\Delta \mathrm{BW}$ & $\Delta \mathrm{cPG}$ & $\Delta$ CPRi & $\Delta \mathrm{BMI}$ & $\Delta \mathrm{SBP}$ & $\triangle \mathrm{DBP}$ & $\Delta$ pulse & $\Delta$ AST & $\Delta \mathrm{ALT}$ & $\Delta \mathrm{Y}$-GTP & $\Delta \mathrm{UA}$ & $\Delta \mathrm{Cr}$ & $\Delta$ eGFR & $\Delta \mathrm{u}-\mathrm{Alb}$ & $\Delta$ Total-C & $\Delta$ LDL-C & $\Delta$ HDL-C & $\Delta \mathrm{TG}$ \\
\hline$\Delta \mathrm{HbA} 1 \mathrm{c}$ & 1.000 & 0.179 & $0.497^{\star}$ & $0.786^{*}$ & 0.145 & 0.077 & 0.029 & 0.111 & 0.164 & $0.244^{*}$ & $0.303^{*}$ & 0.081 & -0.070 & 0.066 & 0.101 & -0.103 & -0.022 & $-0.452^{*}$ & $0.315^{*}$ \\
\hline$\Delta \mathrm{BW}$ & & 1.000 & 0.169 & 0.306 & $0.943^{*}$ & 0.136 & 0.010 & -0.075 & 0.192 & $0.251^{*}$ & $0.279^{*}$ & 0.196 & 0.127 & -0.128 & 0.211 & 0.081 & -0.021 & -0.130 & 0.094 \\
\hline$\triangle \mathrm{CPG}$ & * & & 1.000 & 0.500 & $0.218^{*}$ & 0.131 & 0.012 & $0.220^{*}$ & 0.099 & 0.127 & $0.211^{*}$ & 0.071 & 0.121 & -0.121 & -0.009 & -0.240 & 0.022 & -0.255 & 0.249 \\
\hline$\triangle \mathrm{CPRi}$ & * & & & 1.000 & -0.107 & -0.342 & -0.321 & $\mid-0.464$ & 0.037 & 0.214 & -0.312 & $0.865 *$ & 0.071 & -0.214 & 0.148 & 0.357 & 0.143 & -0.306 & 0.739 \\
\hline$\triangle \mathrm{BMI}$ & & * & * & & 1.000 & 0.131 & -0.064 & -0.039 & 0.101 & 0.161 & 0.199 & 0.094 & 0.092 & -0.081 & 0.225 & 0.077 & -0.044 & -0.134 & 0.113 \\
\hline$\triangle \mathrm{SBP}$ & & & & & & 1.000 & $0.515^{*}$ & * 0.051 & 0.031 & 0.025 & 0.185 & -0.052 & $-0.230^{*}$ & $0.229^{*}$ & 0.057 & $-0.384^{*}$ & 0.011 & $-0.221^{*}$ & 0.077 \\
\hline$\triangle \mathrm{DBP}$ & & & & & & * & 1.000 & -0.010 & -0.010 & 0.032 & 0.043 & -0.082 & $-0.229^{*}$ & $0.213^{*}$ & -0.010 & $-0.301^{*}$ & 0.065 & -0.187 & 0.101 \\
\hline$\Delta$ pulse & & & * & & & & & 1.000 & 0.049 & 0.015 & 0.064 & -0.040 & $0.214^{*}$ & -0.123 & 0.020 & 0.035 & 0.019 & -0.033 & 0.166 \\
\hline$\triangle \mathrm{AST}$ & & & & & & & & & 1.000 & $0.870^{*}$ & * $0.686^{\star}$ & 0.042 & 0.045 & 0.012 & 0.183 & 0.059 & $0.250^{\star}$ & -0.085 & -0.009 \\
\hline$\triangle \mathrm{ALT}$ & * & * & & & & & & & * & 1.000 & $0.734^{*}$ & 0.090 & 0.007 & 0.053 & 0.181 & 0.049 & $0.269^{*}$ & -0.167 & 0.054 \\
\hline$\Delta Y-G T P$ & * & * & * & & & & & & * & * & 1.000 & 0.073 & 0.074 & -0.008 & 0.183 & -0.080 & $0.350^{*}$ & $-0.208^{*}$ & 0.181 \\
\hline$\Delta \mathrm{UA}$ & & & & * & & & & & & & & 1.000 & $0.324^{*}$ & $-0.307^{*}$ & * -0.071 & 0.123 & 0.038 & -0.090 & 0.166 \\
\hline$\Delta \mathrm{Cr}$ & & & & & & * & * & * & & & & * & 1.000 & $-0.924^{*}$ & $|-0.151|$ & 0.101 & 0.085 & 0.079 & 0.024 \\
\hline$\triangle \mathrm{eGFR}$ & & & & & & * & * & & & & & * & * & 1.000 & 0.159 & -0.054 & -0.115 & -0.119 & 0.003 \\
\hline$\Delta \mathrm{u}-\mathrm{Alb}$ & & & & & & & & & & & & & & & 1.000 & 0.037 & -0.135 & -0.050 & -0.106 \\
\hline$\Delta$ Total- C & & & & & & * & * & & & & & & & & & 1.000 & $0.841^{*}$ & $0.257^{*}$ & 0.020 \\
\hline$\Delta \mathrm{LDL}-\mathrm{C}$ & & & & & & & & & * & * & * & & & & & * & 1.000 & 0.136 & -0.055 \\
\hline$\Delta \mathrm{HDL}-\mathrm{C}$ & * & & * & & & * & & & & & * & & & & & * & & 1.0000 & $-0.436^{*}$ \\
\hline$\Delta \mathrm{TG}$ & * & & * & & & & & & & & & & & & & & & * & 1.000 \\
\hline \multicolumn{20}{|c|}{$\begin{array}{l}\text { Correlations among the changes in various parameters after } 12 \text { months of dapagliflozin administration (or final observation) were analyzed using Spearman's rank } \\
\text { correlation coefficient. Missing values were supplemented using the last observation carried forward method. * } p<0.05\end{array}$} \\
\hline $\begin{array}{l}\text { BW: body } \\
\text { excretion }\end{array}$ & ly weight, & PPG: & sual $p$ & sma gluc & $\mathrm{se}, \mathrm{c}$ & PRi: CPF & $R$ index, & , SBP: & pstolic & $\operatorname{ood} p$ & ssure, & BP: di & stolic b & od pre & re, $u$ & : uric & , u-A & urinar & bumin \\
\hline
\end{tabular}

Table 5: Correlations among the changes in various parameters after 12 months of dapagliflozin administration. 
Citation: Kudo T, Abe I, Minezaki M, Sugimoto K, Fujii H, et al. (2018) Investigation of Metabolic and Circulatory Parameters That Predict Effects of Dapagliflozin, a Sodium-Glucose Cotransporter 2 Inhibitor, on Blood Glucose and Body Weight in a Retrospective, Multicenter Study. J Diabetes Metab 9: 810. doi:10.4172/2155-6156.1000810

Page 6 of 7

\begin{tabular}{|l|l|l|l|l|}
\hline \multicolumn{5}{|c|}{ (Change in HbA1c) } \\
\hline $\begin{array}{l}\text { Background } \\
\text { factor }\end{array}$ & $\begin{array}{l}\text { Partial regression } \\
\text { coefficient }\end{array}$ & $\begin{array}{l}\text { Standard } \\
\text { error }\end{array}$ & t-value & p-value \\
\hline HbA1c & -0.4619 & 0.0687 & -6.7212 & $<0.001^{* *}$ \\
\hline HDL-C & 0.012 & 0.0061 & 1.9546 & 0.0537 \\
\hline \multicolumn{5}{|c|}{ (Change in BMI) } \\
\hline $\begin{array}{l}\text { Background } \\
\text { factor }\end{array}$ & $\begin{array}{l}\text { Partial regression } \\
\text { coefficient }\end{array}$ & $\begin{array}{l}\text { Standard } \\
\text { error }\end{array}$ & t-value & p-value \\
\hline Sex\# & 0.495 & 0.216 & 2.2911 & $0.0242^{*}$ \\
\hline Disease duration & -0.0395 & 0.0177 & -2.2344 & $0.0279^{*}$ \\
\hline
\end{tabular}

Table 6: Patient characteristics that affected the changes in $\mathrm{HbAlc}$ and BMI.

\section{Discussion}

Clinical trials of new drugs involve a limited number of patients and short duration of administration. Therefore, data on administration of new drugs to broader patient populations need to be collected in clinical practice. This is particularly important for SGLT2 inhibitors, which have novel mechanisms of action and are expected to exhibit various effects, including protective actions in the cardiovascular system and other organs. The CVD-REAL2 study provided the major real-world evidence on SGLT2 inhibitors [14]. This study compared the cardiovascular risk in patients receiving SGLT2 inhibitors and other antidiabetic drugs, as a part of their daily medical care. This study included more than 400,000 patients with type 2 diabetes from 6 countries, including Japan. Dapagliflozin and other SGLT2 inhibitors reduced the overall mortality risk by $49 \%$ (hazard ratio (HR), 0.51 ; $95 \%$ confidence interval (CI), 0.370.7), risk of hospitalization owing to heart failure by $36 \%(\mathrm{HR}, 0.64 ; 95 \% \mathrm{CI}, 0.50 .82)$, risk of myocardial infarction by $19 \%$ (HR,0.81; 95\% CI,0.740.88), and risk of stroke by $32 \%$ (HR,0.68; 95\% CI,0.550.84). We as clinicians have been interested in the benefits of SGLT2 inhibitors to the cardiovascular system.

In the present multicenter study including 6 medical institutions in the Chikushi region of Kyushu, Japan, we retrospectively examined the effects of dapagliflozin on blood glucose, body weight, blood pressure, uric acid, lipid profiles, liver and kidney function parameters, urinary protein, and other parameters in patients with type 2 diabetes in clinical practice. In addition, we investigated the patient characteristics that affected the changes in HbAlc and BMI.

The main complications of the subjects included in this study were dyslipidemia, hypertension, obesity, and fatty liver, indicating that metabolic syndrome affected many of the subjects. The average age was 56.7 years, showing that young age groups were also included. Patients were obese, had relatively high HbAlc levels, and had been diabetic for a long time. Administration of dapagliflozin improved their blood pressure, liver function parameters (AST, ALT, and $\gamma$-GTP), uric acid, and lipid profiles, which suggested that dapagliflozin might have positive effects on the metabolism and circulatory dynamics. Among these, changes in the liver function parameters, ALT and/or $\gamma$-GTP positively correlated with the changes in $\mathrm{HbAlc}$ and body weightBMI. This indicated that patients in whom dapagliflozin improved HbAlc levels and reduced body weight might also exhibit improved liver functions. Hyperglycemia may increase the transcriptional activity of genes related to lipid synthesis in the liver resulting in fatty liver [15],

and ectopic fats accumulated in the liver can induce insulin resistance [16]. In the present study, we showed that dapagliflozin administration improved hyperglycemia and obesity in patients with type 2 diabetes with complicating metabolic syndrome, which, in turn, suppressed the accumulation of fat in the liver, thereby improving liver functions. Furthermore, other studies found that ALT levels decreased after administration of dapagliflozin or other SGLT2 inhibitors to patients with type 2 diabetes patients [17-20]. In rodents, SGLT2 inhibitors have been found to suppress fatty liver and lower ALT levels [21,22]. In addition, hepatocytes obtained from liver biopsies of patients with type 2 diabetes receiving SGLT2 inhibitors showed reduced fatty changes [23]. Moreover, SGLT2 inhibitors are expected to improve nonalcoholic fatty liver disease (NAFLD), which often complicates type 2 diabetes [24,25]. Interestingly, Changes in ALT, $\gamma$-GTP also positively correlated with the change in LDL-C. This correlation may be due to improved glycemic control and/or insulin resistance as a confounding factor.

Our investigation of the patient characteristics that affected the change in HbAlc showed that patients with high HbAlc levels exhibited larger improvements in HbAlc. A phase III trial of dapagliflozin in Asian subjects showed that the mean $\mathrm{HbA1c}$ declined from $8.26 \%$ at baseline to $7.22 \%$ and $7.15 \%$ after 6-month dapagliflozin administration at 5 and $10 \mathrm{mg}$, respectively [26]. Moreover, dapagliflozin administration to Japanese subjects lowered $\mathrm{HbA1c}$ from $7.5 \%$ at baseline to 7.09 and $7.05 \%$ at doses of 5 and $10 \mathrm{mg}$, respectively [27]. The magnitude of HbAlc change observed in the present study was in between those reported in these previous studies, possibly owing to the different baseline HbAlc values. Furthermore, female sex and long disease duration were associated with large improvements in BMI. These factors are of great interest and merit further investigation in larger populations with analysis of a greater number of background factors to identify patients with type 2 diabetes who are expected to benefit more from dapagliflozin treatment. In terms of safety, dapagliflozin administration did not cause any major side effects, and no clinically meaningful changes were observed in the vital signs or kidney and liver function parameters. Although an increase in urinary tract and genital infections was reported after 4-year dapagliflozin administration, the incidence decreased over time [28]. This indicated that dapagliflozin is relatively safe for clinical use as long as it is administered carefully with full consideration of safety.

According to the IDF Diabetes Atlas 8th Edition in 2017 [29], there were 425 million patients with diabetes worldwide in 2017, and the number is predicted to increase to 629 million by 2045. The number of patients with diabetes is expected to increase in developed countries with the increase in age and obesity. For appropriate treatment diabetes, more effective therapeutic approaches should be established. This multicenter study was planned and conducted in search of more effective therapeutic approaches for diabetes.

\section{Conclusion}

This multicenter study conducted at 6 medical institutions in the Chikushi region of Kyushu confirmed the safety and positive effects of dapagliflozin on blood glucose in clinical practice. Improvements in blood pressure, liver function parameters (AST, ALT, and $\gamma$-GTP), uric acid, and lipid profiles were also observed. Moreover, baseline HbAlc was shown to positively correlate with $\mathrm{HbAlc}$ improvement, and female sex and longer disease duration were related to BMI improvement. This indicated that dapagliflozin might have positive effects on the metabolism and circulatory dynamics. 
Citation: Kudo T, Abe I, Minezaki M, Sugimoto K, Fujii H, et al. (2018) Investigation of Metabolic and Circulatory Parameters That Predict Effects of Dapagliflozin, a Sodium-Glucose Cotransporter 2 Inhibitor, on Blood Glucose and Body Weight in a Retrospective, Multicenter Study. J Diabetes Metab 9: 810. doi:10.4172/2155-6156.1000810

Page 7 of 7

\section{Acknowledgements}

We would like to thank Ms. Yumi Iriguchi for her assistance in clerical procedures for drafting and submitting this manuscript, and Interscience Co., Ltd. for helping with analysis and editing.

\section{Conflict of Interest}

This article was drafted and submitted partially with financial assistance from Ono Pharmaceutical Co. and AstraZeneca PLC.

\section{References}

1. Standards of Medical Care in Diabetes-2018 (2018) Diabetes Care 41: S1S159.

2. Ferrannini E, Solini A (2012) SGLT2 inhibition in diabetes mellitus: rationale and clinical prospects. Nat Rev Endocrinol 8: 495-502.

3. Goring S, Hawkins N, Wygant G, Roudaut M, Townsend R, et al. (2014) Dapagliflozin compared with other oral anti-diabetes treatments when added to metformin monotherapy: A systematic review and network meta-analysis. Diabetes Obes Metab 16: 433-442.

4. Liu XY, Zhang N, Chen R, Zhao JG, Yu P (2015) Efficacy and safety of sodium-glucose cotransporter 2 inhibitors in type 2 diabetes: A metaanalysis of randomized controlled trials for 1 to 2 years. J Diabetes Complications 29: 1295-1303.

5. Zaccardi F, Webb DR, Htike ZZ, Youssef D, Khunti K, et al. (2016) Efficacy and safety of sodium-glucose co-transporter-2 inhibitors in type 2 diabetes mellitus: A systematic review and network meta-analysis. Diabetes Obes Metab 18: 783-794.

6. Shyangdan DS, Uthman OA, Waugh N (2016) SGLT-2 receptor inhibitors for treating patients with type 2 diabetes mellitus: A systematic review and network meta-analysis. BMJ Open 6: e009417.

7. Inzucchi SE, Zinman B, Wanner C, Ferrari R, Fitchett D, et al. (2015) SGLT-2 inhibitors and cardiovascular risk: proposed pathways and review of ongoing outcome trials. Diab Vasc Dis Res 12: 90-100.

8. Kashiwagi A, Maegawa H (2017) Metabolic and hemodynamic effects sodium-dependent glucose cotransporter 2 inhibitors on cardio-renal protection in the treatment of patients with type 2 diabetes mellitus. J Diabetes Investig 8: 416-427.

9. Yokote K, Terauchi Y, Nakamura I, Sugamori H (2016) Real-world evidence for the safety of ipragliflozin in elderly Japanese patients with type 2 diabetes mellitus (STELLA-ELDER): final results of a postmarketing surveillance study. Expert Opin Pharmacother 17: 1995-2003.

10. Kambara T, Shibata R, Osanai H, Nakashima Y, Asano H, et al. (2018) Use of sodium-glucose cotransporter 2 inhibitors in older patients with type 2 diabetes mellitus. Geriatr Gerontol Int 18: 108-114.

11. Elmore LK, Baggett S, Kyle JA, Skelley JW (2014) A review of the efficacy and safety of canagliflozin in elderly patients with type 2 diabetes. Consult Pharm 29: 335-346.

12. Utsunomiya K, Shimmoto N, Senda M, Kurihara Y, Gunji R, et al. (2017) Safety and effectiveness of tofogliflozin in elderly Japanese patients with type 2 diabetes mellitus: A post-marketing study (J-STEP/EL study). J Diabetes Investig 8: 766-775.

13. Goda M, Yamakura T, Sasaki K, Tajima T, Ueno M (2018) Safety and efficacy of canagliflozin in elderly patients with type 2 diabetes mellitus: a 1-year post-marketing surveillance in Japan. Curr Med Res Opin 34: 319-327.

14. Kosiborod M, Lam CSP, Kohsaka S, Kim DJ, Karasik A, et al. (2018) CVD-REAL Investigators and Study Group. Cardiovascular events associated with SGLT-2 inhibitors versus other glucose-lowering drugs: The CVD-REAL 2 study. J Am Coll Cardiol 71: 2628-2639.
15. Wang Y, Viscarra J, Kim SJ, Sul HS (2015) Transcriptional regulation of hepatic lipogenesis. Nat Rev Mol Cell Biol 16: 678-689.

16. Byrne CD, Targher G (2014) Ectopic fat, insulin resistance, and nonalcoholic fatty liver disease: Implications for cardiovascular disease. Arterioscler Thromb Vasc Biol 34: 1155-1161.

17. Lee PCH, Gu Y, Yeung MY, Fong CHY, Woo YC, et al. (2018) Dapagliflozin and empagliflozin ameliorate hepatic dysfunction among Chinese subjects with diabetes in part through glycemic improvement: A single-center, retrospective, observational study. Diabetes Ther 9: 285-295.

18. Katsuyama H, Hamasaki H, Adachi H, Moriyama S, Kawaguchi A, et al. (2016) Effects of sodium-glucose cotransporter 2 inhibitors on metabolic parameters in patients with type 2 diabetes: A chart-based analysis. J Clin Med Res 8: 237-243.

19. Hayashi T, Fukui T, Nakanishi N, Yamamoto S, Tomoyasu M, et al. (2017) Dapagliflozin decreases small dense low-density lipoprotein-cholesterol and increases high-density lipoprotein 2-cholesterol in patients with type 2 diabetes: comparison with sitagliptin. Cardiovasc Diabetol 16: 8.

20. Tobita H, Sato S, Miyake T, Ishihara S, Kinoshita Y (2017) Effects of dapagliflozin on body composition and liver tests in patients with nonalcoholic steatohepatitis associated with type 2 diabetes mellitus: A prospective, open-label, uncontrolled study. Curr Ther Res Clin Exp 87: 13-19.

21. Hayashizaki-Someya Y, Kurosaki E, Takasu T, Mitori H, Yamazaki S, et al. (2015) Ipragliflozin, an SGLT2 inhibitor, exhibits a prophylactic effect on hepatic steatosis and fibrosis induced by choline-deficient l-amino aciddefined diet in rats. Eur J Pharmacol 754: 19-24.

22. Qiang S, Nakatsu Y, Seno Y, Fujishiro M, Sakoda H, et al. (2015) Treatment with the SGLT2 inhibitor luseogliflozin improves nonalcoholic steatohepatitis in a rodent model with diabetes mellitus. Diabetol Metab Syndr 7: 104.

23. Takeda A, Irahara A, Nakano A, Takata E, Koketsu Y, et al. (2017) The improvement of the hepatic histological findings in a patient with nonalcoholic steatohepatitis with type 2 diabetes after the administration of the sodium-glucose cotransporter 2 inhibitor ipragliflozin. Intern Med 56: $2739-2744$

24. Ludwig J, Viggiano TR, McGill DB, Oh BJ (1980) Nonalcoholic steatohepatitis: Mayo Clinic experiences with a hitherto unnamed disease. Mayo Clin Proc 55: 434-438.

25. Vernon G, Baranova A, Younossi ZM (2011) Systematic review: the epidemiology and natural history of non-alcoholic fatty liver disease and non-alcoholic steatohepatitis in adults. Aliment Pharmacol Ther 34: 274-285.

26. Ji L, Ma J, Li H, Mansfield TA, T'joen CL, et al. (2014)Dapagliflozin as monotherapy in drug-naive Asian patients with type 2 diabetes mellitus: a randomized, blinded, prospective phase III study. Clin Ther 36: 84-100.

27. Kaku K, Kiyosue A, Inoue S, Ueda N, Tokudome T, et al. (2014) Efficacy and safety of dapagliflozin monotherapy in Japanese patients with type 2 diabetes inadequately controlled by diet and exercise. Diabetes Obes Metab 16: 1102-1110.

28. Del Prato S, Nauck M, Durán-Garcia S, Maffei L, Rohwedder K, et al. (2015) Long-term glycaemic response and tolerability of dapagliflozin versus a sulphonylurea as add-on therapy to metformin in patients with type 2 diabetes: 4-year data. Diabetes Obes Metab 17: 581-590.

29. http://diabetesatlas.org/IDF_Diabetes_Atlas_8e_interactive_EN/ 